\title{
Patterns of Population and Urban Growth in Southwest Europe: 1920-20 I0
}

Journal of Urban History 2017, Vol. 43(6) I02I-1040 (C) The Author(s) 2017

Reprints and permissions: sagepub.com/journalsPermissions.nav DOI: $10.1177 / 0096 \mid 44217726974$ journals.sagepub.com/home/juh

\author{
Cathy Chatel', Mateu Morillas-Torné2, Albert Esteve ${ }^{3}$, \\ and Jordi Martí-Henneberg ${ }^{2}$
}

\begin{abstract}
This work seeks to measure, locate, and explain changes in the distribution of population and urban growth in the territory formed by France, Italy, and the Iberian Peninsula between 1920 and 2010. This is based on population data of more than fifty-six thousand local units obtained from population censuses: the Geokhoris database that we built. Our starting viewpoint is that it is only possible to understand the extent of the urbanization process within the context of the evolution of all of the municipalities. The description of the distribution and growth of population at the local level shows the population concentration in the various urban agglomerations, and, since 1970, a relative deconcentration and extension of the cities. Within this context, a regression model helped us to identify the geographic factors that correlate with these fundamental transformations in population geography, which were also indicative of new forms of social organization within the territory.
\end{abstract}

\section{Keywords}

population change, urbanization, linear regression, database, southwestern Europe

\section{Introduction, Overview, and Literature}

The twentieth century is characterized by the urbanization process. Authors who have analyzed the recent history of settlement have tended to focus most of their attention on the growth of cities, whereas rural depopulation has been treated separately and largely forgotten. This separation has worked against a combined interpretation of the two phenomena and a joint vision and explanation of today's distribution of population. Here, we seek to analyze the evolution of the whole territory. Starting from the theoretical framework of path dependency and the use of scale in geography, ${ }^{1}$ this research argues that the structure of the distribution of population tends to condition its future dynamics and that its evolution is essential for interpreting the current reality. From this viewpoint, we shall demonstrate that it is only possible to understand the extent of the urbanization

'FAPESP (Fundação de Amparo à Pesquisa do Estado de São Paulo), UNESP (Universidade Estadual Paulista "Júlio de Mesquita Filho"), Presidente Prudente, São Paulo, Brasil

¿Universitat de Lleida, Lleida, Spain

${ }^{3}$ Centre d'Estudis Demogràfics Universitat Autònoma de Barcelona, Barcelona, Spain

\section{Corresponding Author:}

Cathy Chatel, FAPESP (Fundação de Amparo à Pesquisa do Estado de São Paulo), UNESP (Universidade Estadual Paulista "Júlio de Mesquita Filho"), Campus Presidente Prudente SP, Rua Roberto Simonsen, 305, Presidente Prudente, São Paulo 19060-900, Brazil.

Email: chatelcathy@yahoo.fr 
process within the context of the evolution of the population of all of the local units within a given area of influence. It had not previously been possible to adopt an approach such as this because it requires a historical database in geographic information system (GIS) format of the type that we have created and used here for the first time. This database, named Geokhoris, covers the population figures of all 56,834 local units in the territory that has been studied, as we will detail in the section "Data and Method." Using this solid background, we have been able to contribute an innovative perspective and methodology for analyzing changes in the distribution of population in the study area, which we shall refer to here as Southwestern Europe (hereinafter, SW Europe).

Although, as we shall see, there have previously been some partial contributions to this debate, to date, there has not been an analysis, or even a description, that has examined a set of several countries in Europe over an extended period, such as a century. This article offers an explanatory vision of a large area that could be replicated in other parts of the world. The data available will allow us to examine the evolution of population in SW Europe over the last ninety years from a historical perspective. This territory is particularly interesting for the type of analysis proposed here because of the numerous differences observed in the dynamics of its mountain areas, plains, coasts, urbanization, and socioeconomic characteristics, some of which have even been diametrically opposed. This variety will make it easier to obtain significant results when we analyze how the different factors included in this study of changes in the distribution of population actually operate. This approach has made it possible to undertake a historical analysis. The description of the phenomena has also been complemented by the identification and measurement of the factors that explain the changes observed. A second aspect of our methodology has been the use of the GIS format, which has allowed us to interrelate data and to exploit them at various scales: national, regional, and local.

This article essentially examines two questions: (1) how the population of SW Europe has evolved, and, more specifically, in which areas, and during which periods, processes of sustained concentration and depopulation have been observed; and (2) the extent to which geographic factors can explain the dynamics of population and how their influence has varied over space and time.

Our hypotheses are twofold: first, that the distribution of population prior to 1920 has conditioned its subsequent evolution, and second, that each of the factors considered has had a different influence on the distribution of population, with this varying according to the area and period under consideration. In this last sense, for instance, the proximity to an administrative capital or to a major urban agglomeration are factors that tended to attract population during the first stage. In contrast, in the last decades of the twentieth century, these same factors often had a negative influence on urban growth. This can be explained by the fact that people initially moved to provincial or national capitals, attracted by "pull" factors, such as the fact that they usually offered more employment, whereas they later tended to leave capitals and move to nearby cities as a result of "push" factors, such as the factors relative to diseconomies of scale, urban congestion, pollution, a declining quality of life, or the high price of housing. Even so, other factors, including the height above sea level of certain local units or their distance from the coast or from an international border had specific influences throughout the period considered. Elevation tended to have a negative influence, whereas proximity to the coast was positive. As a result, the population size of each local unit has an important influence on its growth (path dependency). Furthermore, the population of urban agglomerations with more than one million inhabitants increased less than medium-sized and small ones, particularly at the beginning of the period studied. Even so, and as we shall see, the intensity of these influences has tended to vary according to the historical period and geographical area.

In this article, we have begun by describing the data to quantify and interpret these processes. This first step was necessary given the lack of precedents in this area. This is a reference that will later be used to evaluate the results of the model and, more specifically, the influence of the physical, political, and socioeconomic factors. 
This article has been organized into the following sections. First, we evaluate the existing literature on this subject. Then, we present the data and methodology, including the indicators that were used. After that, we describe the evolution of population in the four countries studied. Then, we present a regression model to calculate the correlation between population growth and a set of factors. Finally, we present our conclusions.

\section{Literature}

Some authors have contributed general reflections that have served to define our theme. First, we would like to underline the fact that our study of local phenomena does not imply a purely local focus. Along these lines, Massey ${ }^{2}$ calls for a vision of "the local" that does not imply a return to the backward-looking idea according to which the identities of people are confined by a limited territory. As far as the use of scale is concerned, we subscribe to Massey's opinion that "we need to conceptualise space as something constructed out of interrelations and as the simultaneous coexistence of social interrelations and interactions at all spatial scales, from the most local to the most global." Also along this line, Smith ${ }^{3}$ highlights the local strategies that form part of a neoliberal urban orientation. We have also taken into account the views of Brenner ${ }^{4}$ who criticizes the concept of "politics of scale," conceiving scale "essentially as a boundary separating the unit in question - be it a place, a locality, a territory or any other spatial form - from other geographical units or locations." We, therefore, insist on our interest in using what is local as a way of approaching the study of what is global.

Until now, very few contributions have sought to explain the changes in the population geography of various different countries over relatively long periods. This is a complex task given the quantity of factors that intervene and how their relative importance changes over time ${ }^{5,6}$ and space. ${ }^{7}$

Work produced to date has centered on Europe in the nineteenth century, ${ }^{8}$ Ireland in the period 1966-1991, ${ }^{9}$ France and Great Britain in the nineteenth century, ${ }^{10}$ and, most recently, modern-day Spain. ${ }^{11}$ It is particularly noteworthy that the three volume Histoire des populations de l'Europe [History of European Population $]^{12}$ does not directly address the subject of the distribution of population.

Of these works, the research of Bairoch and Goertz ${ }^{13}$ could perhaps be considered a precedent to our studies, but it was carried out without the use of GIS tools or a database covering all of the local units. These authors did include data and possible explanatory variables, but only for the national level. Their variables referred to gross national product (GNP) at the national level, the level of industrialization, percentage of exportations with respect to GNP, productivity of agriculture, production of cereals over domestic consumption, percentage of immigrant population, railways, degree of administrative centralization, and percentage of urban with respect to total population. Of all of these factors, those that most clearly explained urbanization turned out to industrialization and economic growth; the factor that least explained it was the railway network, according to these authors.

Lutz $^{14}$ subsequently conducted a study on Ireland and carried out a multiple regression to analyze changes in urban population based on eighteen explanatory variables. As in the previous case, Lutz used different variables from those in the present article. These factors included the distance from each of the three capitals (national capital and counties capitals) of Dublin, Cork, and Limerick; the percentage of people employed in different economic sectors; and the percentage of men and women not gainfully employed in each city. He concluded that the most relevant factor was proximity to Dublin and that this was particularly true for municipalities located in the same county.

Schwartz et al. ${ }^{15}$ based their historical geography analysis on GIS, focusing on rural society in France and Great Britain. In it, they described the local and regional differences associated with uneven economic, demographic, and cultural change. Within this field, the railway was seen as playing an important role in restructuring rural economies, as it made it possible to open new markets and offered new opportunities for work. For a time, this circumstance helped to postpone rural depopulation in those communities that were served by rail services. 
More recently, Franch, Martí-Henneberg and Puig-Farré16 carried out a Global Moran I analysis to confirm the spatial autocorrelation of population density in Spain during the twentieth century, which continually increased in the course of the century and over the eleven censuses analyzed between 1900 and 2011. Based on this analysis, they located clusters using the Local Moran I indicator. They also measured how the population of Spain has tended to concentrate around existing cities and near to the coast.

Turok and Mykhnenko ${ }^{17}$ focused their attention on the long-term evolution of the population of 310 European cities with more than two hundred thousand inhabitants. Their objective was to track the evolution of the population of these cities (indicating any possible individual demographic trajectories) and then, to check whether there were any factors that correlated with this urban growth. The variable used was population change, which was considered a consequence of, but also an influence on, urban and particularly economic conditions.

Using data at the regional level, Marti-Henneberg ${ }^{18}$ integrated population for the whole of Europe. In this study, he carried out a spatial correlation of the density of population between the years 1870 and 2000 , obtaining an $r^{2}=.83$. In other words, 83 percent of the regional density of population in 2000 could be explained by that of 1870 . This path dependency scheme showed that the most populated regions in 1870 were generally the ones that grew most until 2000 . Behind these disparities in growth lay mainly human factors - such as the establishment of transport networks - but also, more permanent, geographic ones.

Finally, it is also interesting to observe what has happened in the United States, where population growth over the last fifty years (1960-2010) has particularly favored the large metropolitan suburbs (132\% increase), followed by small metropolitan areas $(81.5 \%)$, and urban counties $(80 \%)$. In contrast, among the smallest settlements, rural counties have grown by only 19 percent, the metropolitan population by 53 percent, and the large metropolitan core counties by 56 percent, ${ }^{19}$ while the central portion of the cities generally lost inhabitants.

Several studies have been based on historical GIS, which allow us to develop both historical and spatial analysis. Most of the methodological studies used to improve the historical geographic information system (HGIS) were carried out in the United Kingdom and United States, ${ }^{20}$ and the results from several of the projects are now available online either as Internet portals ${ }^{21}$ with their own contents, or through publications. ${ }^{22}$ Among the latter, we would underline publications that include works and atlases about Spain, Portugal, and France that are based on historical, statistical, and administrative sources. They also exceptionally provide information about the history of their territorial units, from the local to the national scale, which is particularly stable. ${ }^{23}$

We shall now go on to present the database in GIS format, which is what allowed us to propose a specific methodology and to obtain the results that we shall subsequently present.

\section{Data and Method}

This study is based on population data at the local level that are used to measure the factors that would explain the growth or decline of population in different areas. Two sets of data were used in this study: total population of local units taken by us from official censuses and homogenized at ten-year intervals, and specific indicators applied to each local unit. Previous work on aerial interpolation served as the reference for this approach. ${ }^{24}$

The source used for population data was the 2012 update of the Geokhoris database ${ }^{25}$ that we have created. Geokhoris uses original sources: population censuses covering the whole territory of each state taken at ten-year intervals. These sources guaranteed the homogeneity of the spatial data used, which was an essential condition for this research. The local unit is the smallest territorial unit for which we were able to find census data for the longest period. The local units in Geokhoris are, therefore, necessarily different according to the countries, and that is why, in the article, we always refer to "local unit," which is a more generic term than "municipality." Most of the time, the local unit used is an administrative unit. This is the unit preferred by the 
Table I. The Geokhoris and Geopolis Database: Local Administrative Units (LAU) and Urban Agglomerations (UA) in France, Spain, Portugal, and Italy.

\begin{tabular}{|c|c|c|c|c|c|c|c|c|c|}
\hline & \multirow{2}{*}{$\begin{array}{c}\text { No. Local } \\
\text { Administrative } \\
\text { Units (LAU) }\end{array}$} & \multicolumn{4}{|c|}{$\begin{array}{l}\text { No. urban agglomerations } \\
\text { (UA) }\end{array}$} & \multicolumn{4}{|c|}{ Total urban population } \\
\hline & & 1920 & 1950 & 1980 & 2010 & 1920 & 1950 & 1980 & 2010 \\
\hline Spain & 8,115 & 255 & 350 & 423 & $46 I$ & $8,049,341$ & $14,176,068$ & $26,848,099$ & $38,416,109$ \\
\hline France & 36,569 & 238 & 305 & 411 & 475 & $13,869,765$ & $18,364,047$ & $33,276,574$ & $40,047,620$ \\
\hline Italy & 8,095 & 555 & 691 & 742 & 588 & $|7,462,59|$ & $25,089,616$ & $38,460,215$ & $47,678,891$ \\
\hline \multirow[t]{3}{*}{ Portugal } & 4,055 & 29 & 62 & 103 & 75 & $1,214,156$ & $2,545,594$ & $4,919,978$ & $7,674,970$ \\
\hline & & \multicolumn{4}{|c|}{$\begin{array}{l}\text { Percentage urban } \\
\text { population }\end{array}$} & \multicolumn{4}{|c|}{ Total population } \\
\hline & & 1920 & 1950 & 1980 & 2010 & 1920 & 1950 & 1980 & 2010 \\
\hline Spain & & 38 & 51 & 72 & 81 & $21,313,722$ & $28,006,769$ & $37,361,266$ & $47,159,473$ \\
\hline France & & 36 & 44 & 62 & 64 & $38,947,293$ & $41,607,229$ & $53,780,913$ & $63,066,860$ \\
\hline Italy & & 44 & 53 & 68 & 79 & $39,303,974$ & $47,223,440$ & $56,208,223$ & $60,488,290$ \\
\hline Portugal & & 20 & 30 & 50 & 73 & $6,128,067$ & $8,530,444$ & $9,760,345$ & $10,537,832$ \\
\hline
\end{tabular}

Sources: Geokhoris, 20II. Geopolis, 20II. C. Chatel, 2012.

institutions that use statistics to publish their data. This is the "commune" in the case of France, the "comune" in Italy, and the "municipio" in Spain. In Portugal, it could be the "concelho," but this one is a large unit. To improve the level of data precision, the preferred local unit used in the Geokhoris database is the "freguesia," which is a smaller administrative unit than the concelho and has its origins in parish units.

The raw data used consisted of census data that were then harmonized with regard to the reference years and local units to make them comparable. This operation was necessary to achieve the spatial and temporal homogeneity required of the data series. The first problem to overcome was that some of the local boundary units changed over time. ${ }^{26}$ To do this, the population data were reconstituted and adjusted to fit the administrative structure corresponding to the latest census that we had used. This was an update of harmonized data for 2010 (based on the censuses of 2009 for France, and 2011 for Italy, Spain, and Portugal; Table 1). The population update has been facilitated in European countries by the fact that administrative boundary changes at the local scale have favored the merging of territorial units rather than their dismemberment. For example, in the case of the recent merging of local units, the populations of the local administrative units in use in 2010 are a result of the sums of the populations of the former local units that have been merged to create them. The second challenge was the fact that the censuses of different states related to different dates; we, therefore, had to deal with temporal heterogeneity and overcame this problem by interpolating population data for years ending in 0 (corresponding to the end of each decade).

It should be noted that the sources of the variables used in the model had different origins. The evolution of the railway network for each decade between 1920 and 2010 was derived from the project "HGISe: Railways, Road and Waterways". ${ }^{27}$ This is a database of the standard gauge railway lines in each country, which does not include narrow gauge lines in Europe. Historical information relating to the opening and closure of lines has been structured with respect to years ending in zero in each decade ${ }^{28}$; the logic, therefore, coincides with that used for interpolating the population data. The mapping of coastlines, rivers, and relief was obtained from Eurostat/Gisco data, whereas we reproduced the historical national borders ourselves. ${ }^{29}$ The population data of urban agglomerations were derived from the Geopolis database. In the Geopolis database, an "urban agglomeration" was defined as a continuous, and uninterrupted, built-up area with a 
population of least ten thousand people and without internal areal discontinuities of more than $200 \mathrm{~m} .{ }^{30}$ Urban agglomerations are the result of the integration of the geographical extension of built areas identified from maps and satellite images, merged with population figures for each local unit from the Geokhoris database. Administrative information about status of local units and their localization/geographical coordinates were derived from the Geokhoris database.

To associate the data series and to calculate their correlation to population growth (the dependent variable), all the variables had to be standardized. It should be noted that in some small settlements, some changes in the number of local inhabitants produced extraordinary annual rates of population growth and that this could give rise to some incoherent regressions. With this in mind, the annual rates of change were, therefore, recalculated using a smoothing technique. ${ }^{31}$ This proved particularly useful when the merging of several different local units resulted in unexpected increases in population that were not matched by real changes in population. ${ }^{32,33}$

The variables used to analyze changes in population at the local level related to the physical, political, economic, urban, and historical context. They were chosen according to their significance and availability for all local units. It was assumed that they could explain the distribution of population and its geographical contrasts with respect to growth over time.

The ten factors that we considered most relevant, and for which we were able to obtain comparable data at the local level (Figure 1), were then classified according to their scale. At the national scale, the key factors were (1) the state to which each local unit belonged, (2) their distance from the nearest national border, and (3) their distance from the national capital. At the regional scale, they were (4) distance of each local unit from the capital of each "province" (as regional districts are known) in Italy and Spain, "département" in France, and "distrito" in Portugal. At the local scale, they were (5) the distance from the center of the nearest urban agglomeration, (6) the distance from the nearest large urban agglomeration (with more than five hundred thousand inhabitants), (7) the distance from the coast, (8) their altitude, (9) the historical population, and (10) their distance from the nearest railway. Some of the indicators were serial data, whereas others were not. ${ }^{34}$

In this way, we calculated the proportion to which each of the indicators was correlated to population growth. Our methodology aims to verify if the current trends observed in population geography can be explained in terms of the geographical and political conditions of each area. This is what we shall study in the next two sections, in which we shall first describe and then analyze the results obtained in this study.

\section{Descriptive Analysis}

The modern era has witnessed the most dramatic demographic change in the history of SW Europe. Between 1800 and 2010, Spain saw its population multiply by 4.4, while in Italy and Portugal, it increased 3.5 fold, and in France, it more than doubled (multiplying by 2.2). During the period that we shall analyze in this article (1920-2010), this growth was also significant, as the populations of Italy and France both grew from forty to more than sixty million, that of Spain from twenty to forty-seven million, and that of Portugal from six to 10.5 million. Our method for identifying and measuring these transformations at the local level allowed us to study how this process was mirrored in the territory and, more specifically, to observe the transformation from a rural to an urban society, as the concentration of population was the most spectacular result observed. Our historical analysis has made it possible to show that the urbanization process was somewhat delayed in these countries, but it was also very rapid once it had begun. Similarly, it was possible to observe clear differences between countries: the national population was predominantly urban (more than 50\%) from 1950 in Spain and Italy, from 1960 in France, and from 1980 in Portugal (Figure 2), whereas the rural exodus was common to all of these countries and particularly affected mountain areas (see map series in the appendix). The metropolitanization of 


\begin{tabular}{|c|c|}
\hline Name of factors & \\
\hline \multicolumn{2}{|c|}{ Altitude (5 variables) } \\
\hline Less than 100 metres & Between 100 and 300 metres \\
\hline Between 300 and 600 metres & Between 600 and 1,000 metres \\
\hline \multicolumn{2}{|l|}{ More than 1,000 metres } \\
\hline \multicolumn{2}{|c|}{ Country (4 variables) } \\
\hline Municipalities in France & Municipalities in Italy \\
\hline Municipalities in Spain & Municipalities in Portugal \\
\hline \multicolumn{2}{|c|}{ Distance from an international border (11 variables) } \\
\hline Less than $25 \mathrm{~km}$ from the Portuguese-Spanish border & Less than $25 \mathrm{~km}$ from the Spanish-French border \\
\hline Less than $25 \mathrm{~km}$ from the French-Belgian border & Less than $25 \mathrm{~km}$ from the French-Luxembourg border \\
\hline Less than $25 \mathrm{~km}$ from the French-German border & Less than $25 \mathrm{~km}$ from the French-Swiss border \\
\hline Less than $25 \mathrm{~km}$ from the French-Italian border & Less than $25 \mathrm{~km}$ from the Italian-Swiss border \\
\hline Less than $25 \mathrm{~km}$ from the Italian-Austrian border & Less than $25 \mathrm{~km}$ from the Italian-Yugoslavian border \\
\hline \multicolumn{2}{|l|}{ More than $25 \mathrm{~km}$ from any international border } \\
\hline \multicolumn{2}{|c|}{ Distance from the coast (5 variables) } \\
\hline Less than $25 \mathrm{~km}$ from the Mediterranean coast & Less than $25 \mathrm{~km}$ from the Atlantic coast \\
\hline Less than $25 \mathrm{~km}$ from the North Sea coast & Less than $25 \mathrm{~km}$ from the Adriatic coast \\
\hline \multicolumn{2}{|l|}{ More than $25 \mathrm{~km}$ from any coast } \\
\hline \multicolumn{2}{|c|}{ Distance from the centre of an agglomeration (4 variables) } \\
\hline Less than $25 \mathrm{~km}$ & Between 25 and $50 \mathrm{~km}$ \\
\hline Between 50 and $100 \mathrm{~km}$ & More than $100 \mathrm{~km}$ \\
\hline \multicolumn{2}{|c|}{ Distance from the national capital (4 variables) } \\
\hline Less than $25 \mathrm{~km}$ from the national capital & Between 25 and $50 \mathrm{~km}$ from the national capital \\
\hline Between 50 and $100 \mathrm{~km}$ from the national capital & More than $100 \mathrm{~km}$ from the national capital \\
\hline \multicolumn{2}{|c|}{ Distance from the provincial capital (4 variables) } \\
\hline Less than $25 \mathrm{~km}$ from the provincial capital & Between 25 and $50 \mathrm{~km}$ from the provincial capital \\
\hline Between 50 and $100 \mathrm{~km}$ from the provincial capital & More than $100 \mathrm{~km}$ from the provincial capital \\
\hline \multicolumn{2}{|c|}{ Distance from a major urban agglomeration (2 variables) } \\
\hline Less than $25 \mathrm{~km}$ & More than $25 \mathrm{~km}$ from a major urban agglomeration \\
\hline \multicolumn{2}{|c|}{ Distance from a standard gauge railway line ( 2 variables) } \\
\hline Less than $25 \mathrm{~km}$ from a railway line & More than $25 \mathrm{~km}$ from a railway line \\
\hline \multicolumn{2}{|c|}{ Size of the settlement ( 9 variables) } \\
\hline Fewer than 500 inhabitants & Between 500 and 1,000 inhabitants \\
\hline Between 1,000 and 5,000 inhabitants & Between 5,000 and 10,000 inhabitants \\
\hline Between 10,000 and 50,000 inhabitants & Between 50,000 and 100,000 inhabitants \\
\hline Between 100,000 and 500,000 inhabitants & Between 500,000 and $1,000,000$ inhabitants \\
\hline More than $1,000,000$ inhabitants & \\
\hline
\end{tabular}

Figure I. Indicators/independent variables.

the most densely populated regions, and even of the most densely populated rural regions, has resulted in extended agglomerations that have ended up merging. In Italy and Portugal, the number of agglomerations decreased between 1980 and 2010, whereas their percentage of the total urban population noticeably increased. 


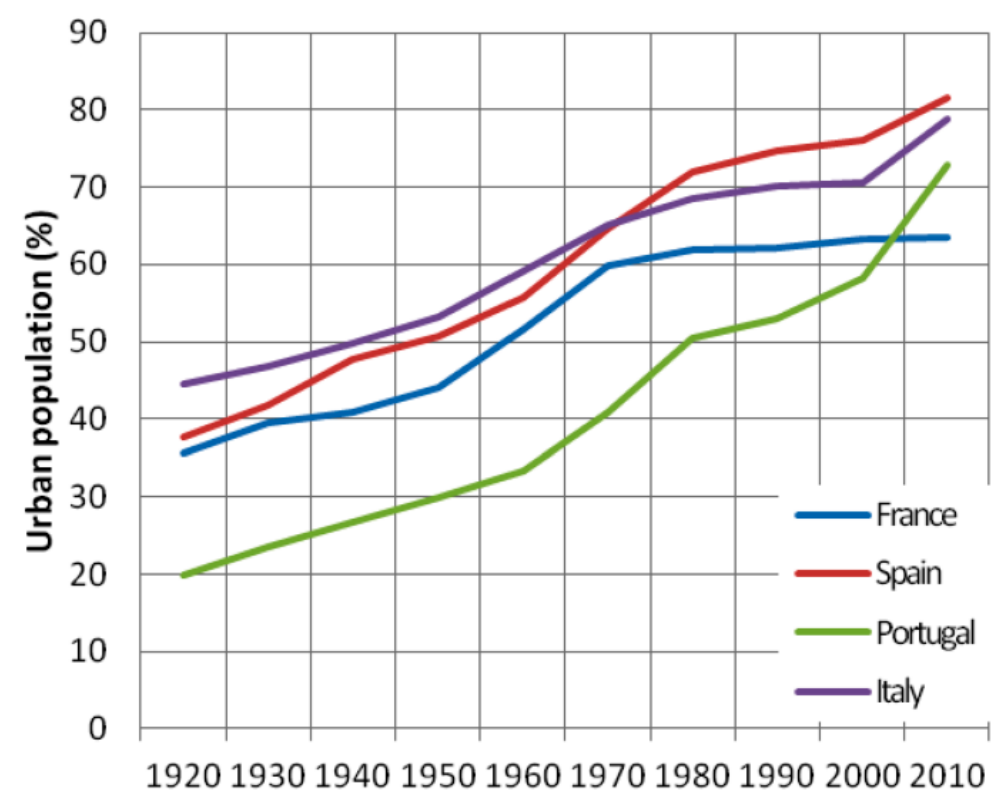

Source : Europolis / e-Geopolis 2012

Figure 2. Evolution of the rate of urbanization 1920-2010: France, Spain, Portugal, and Italy.

The evolution of the number of urban agglomerations between different areas and countries presents differences relating to their respective positions in a previous urban network or which have implied the creation of completely new agglomerations. Thus, Italy, with a solid urban history, had a large number of existing urban agglomerations and, therefore, the 555 agglomerations registered in 1920 had only risen to 588 by 2010 . Portugal was less urbanized, with only seventy-five urban agglomerations in 2010. In both France and Spain, the number of urban agglomerations increased from about 250 in 1920 to nearly 500 in 2010 (Table 1). The composition of these agglomerations depended on the number and size of the local units forming them, which vary considerably across the area of SW Europe included in this study. In SW Europe, urban agglomerations were characteristically composed of small local units as there had been relatively little administrative reform compared with what had occurred in most of the other countries in Europe. As a result, the four countries that we have analyzed largely maintained their nineteenth-century local structures, predominantly composed of small ${ }^{35}$ units (Table 1). Thus, in the four countries, urban agglomerations can include several local units, whereas it is quite rare to record a local unit including several urban agglomerations. Another relevant difference was that France was dominated by its capital, whereas in the other three Mediterranean countries, the political capitals were counterbalanced by one or more other major cities. ${ }^{36}$

If we now look at all the population data, we see that the distribution of population in SW Europe followed a series of both general and specific trends, depending on each state. Among the general ones, we should highlight a tendency for the number and size of urban agglomerations to multiply, which is mostly explained both by demographic increase and by rural push factors. Once established, urban centers tended to stimulate their surrounding areas, and this was particularly evident after decreases in the density of population in inner city areas. Thus, cities such as Madrid, Rennes, Nantes, Le Mans, and Tours (Figures 3 and 4) were characterized by decreasing population densities, with movement from the center to the periphery following a monocentric model. However, other urban 


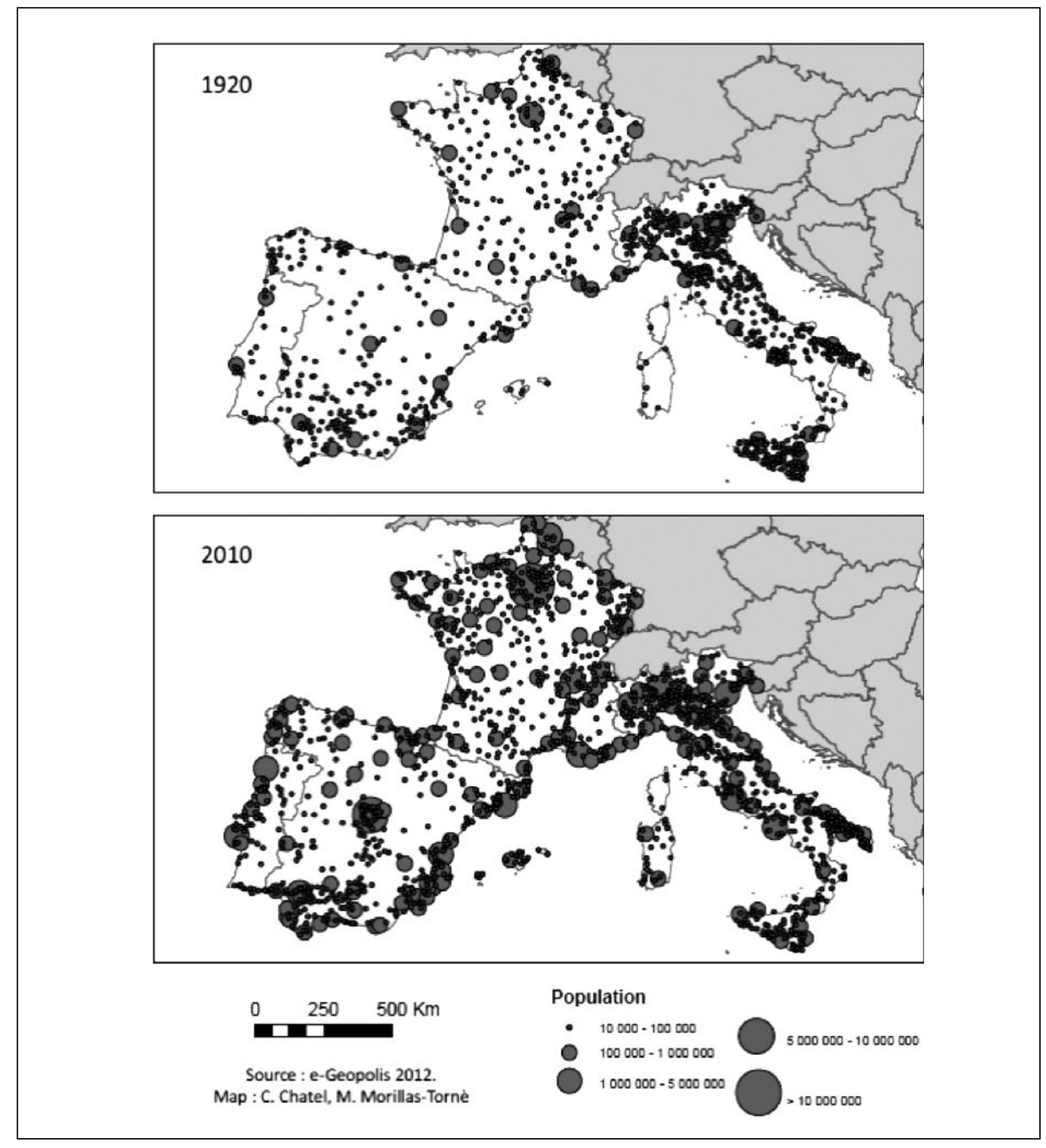

Figure 3. Population by urban agglomerations: 1920 and 2010 .

agglomerations, particularly in France, exhibited a different trend, with Paris, Lyon, Toulouse, Bordeaux, and Grenoble emerging as inland nodes and contributing to the formation of several dense urban axes. Meanwhile, urban agglomerations located on the coast tended to induce the growth of linear urban settlements along the coast. As a result, an almost continuous urbanized space developed from southern Spain to Tuscany, with population densities exceeding 100 per $\mathrm{km}^{2}$. A similar phenomenon can be observed along the Atlantic coast, from La Coruña in Galicia to Setubal in Portugal.

Even so, the distribution of population exhibits certain specific characteristics in each state. Inland Spain, for example, has been immersed in a process of depopulation that contrasts with population growth in Madrid, along the Mediterranean coast, and in and around the cities of the Atlantic coast: San Sebastian, Bilbao, Santander, Gijón, La Coruña, and Vigo.

In general, the evolution of the urban agglomerations has reflected the distribution of population, as there has been a general tendency for the majority of the population to become increasingly 


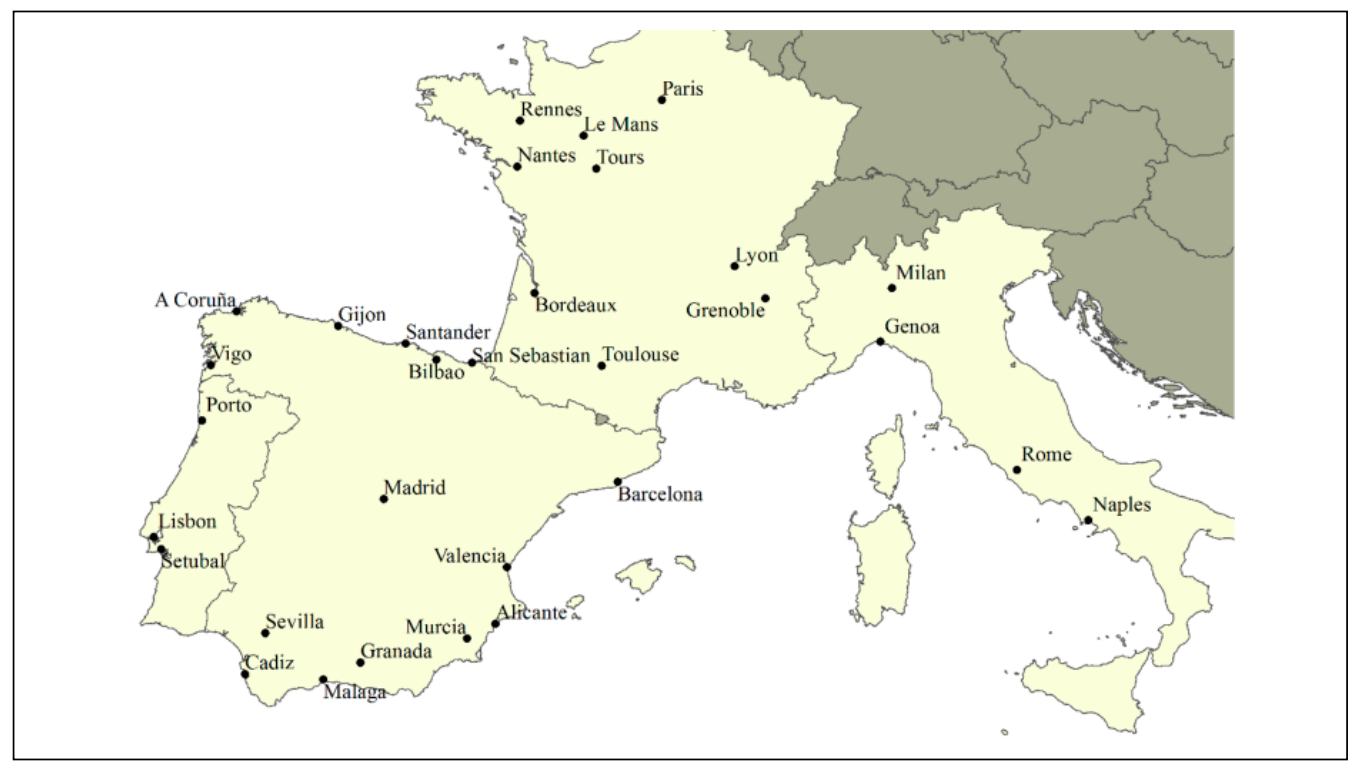

Figure 4. Map of main toponyms [main place names mentioned in the text].

urban. If we compare the situation in 1920 with that in 2010 (Figure 3), it is possible to observe a general trend toward increased population densities, with only the rural interior of the Iberian Peninsula, which is an area of historically low population density, being excluded from this tendency. Something similar was also observed in Italy, but to a much lesser degree.

In the case of France, the mountainous areas of the Alps and the Massif Central - the so-called "empty diagonal" - were hit by rural exodus and excluded from the general dynamic of growth. The initial distribution of population was transformed by the emergence of higher densities in certain specific areas: the corridor from Lyon and the region of Savoie to the Mediterranean coast, following the Rhône Valley; the regions of Bordeaux, Toulouse, Alsace-Lorraine, and the Jura; and the northwest of the country.

The process of metropolitanization began in France around 1970, when it was also observable, albeit to a lesser extent, in Italy, Portugal, and Spain. In France, large metropolitan areas were formed as a result of generalized growth, which particularly benefited the rural areas around urban agglomerations at the expense of city centers. In other countries, the phenomenon was seen in areas of growth that gradually emerged and extended over time. In fact, population growth in Spain tended to remain highly concentrated, with the evolution of Madrid and of settlements along the Mediterranean coast contrasting with tendencies observed in the rest of the country. The general situation was one of SW Europe experiencing deep-seated changes throughout the study period as a result of a combination of population growth and urbanization. The maps of population density in 1920 and 2010 show completely different structures (see the appendix). By the twenty-first century, large and medium-sized urban agglomerations had spread across the different national territories and along their coastlines. Indeed, they had become crucial for understanding the territorial structure of SW Europe.

This previous descriptive presentation highlights the relevance of a factorial analysis if we want to understand the changes that have occurred and the present distribution of population. We shall now go on to explain this population evolution based on the proposed variables, and we will check whether the model is able to contribute a more closely honed interpretation of the processes observed to date. The figure in the appendix maps the evolution of population at the local scale for each decade during the period 1920-2010. These maps provide a geographic perspective of the evolution of population and, therefore, help us to understand it. 


\section{Analysis of Factors}

In the previous section, we observed how the population of SW Europe grew between 1920 and 2010, and how its distribution pattern changed. The objective of this section is to identify the factors that have most influenced this process and to explain the modifications in terms of population distribution patterns. To do this, we used a linear regression model in which we included the distance of each local unit from the center of the nearest urban agglomeration, a national or provincial capital, the railway network, the coast, and a national border. We also included such indicators as absolute population at ten-year intervals, the evolution of population throughout each decade, altitude, and the country to which the local unit in question belonged.

The linear regression based on these variables produced beta values that measure the influence of each of the explanatory variables with respect to the dependent variable. In other words, they measure its intensity and how influential it is (Table 2).

Each of these indicators was categorized into a number of different binary variables, into which the different local units were grouped according to their respective values. In this way, each local unit was assigned a unique variable for each indicator.

Linear regression analysis was carried out for each separate indicator, with all of the different variables of the indicator being used. This operation was repeated for each decade from 19201930 through to 2000-2010:

$$
y=\beta_{0}+\beta x_{1}+\beta x_{2}+(\ldots)+\beta x_{n},
$$

where " $y$ " is the dependent variable (population growth), " 0 " is the constant term, and " $\beta$ " is the parameter that quantifies the extent and proportion to which each independent variable $\left(x_{1}, x_{2} \ldots\right)$ influences the equation. The higher the value of $\beta$, the more significant the result will be (between -0.001 and 0.001 , the results are not significant). For each indicator, the value of $\beta$ for a specific class and period is related to the $\beta$ value recognized in the other classes. For this reason, each indicator contains a class labeled "for reference." In this, $\beta$ does not have a value, and the rest of the classes are calculated with respect to it. For example, for the indicator relating to "distance from the national capital" during the period 1920-1930, we found that beyond a distance of 100 $\mathrm{km}$ from the capital, $\beta$ had a value of -0.024 . This indicates that the variation in the population was 2.4 percent less intense than that experienced by the local units located within $25 \mathrm{~km}$ of the capital. From this, it is possible to deduce the positive influence of proximity to the capital upon variation in the populations of local units.

Analyzing the whole results (Table 2), the identification of the maximal and minimal beta values (Table 3), and their amplitude shows clearly the most relevant factors that we classified in five themes. Factors relating to the territorial organization of the State (Factors: "country," "distance from the national capital," "distance from the provincial capital," "distance from an international border"; Tables 2 and 3) and to the location and size and the place of the concentrations of population (Factors: "size of settlement (population)," "distance from a major urban agglomeration," "distance from the center of an agglomeration"; Tables 2 and 3) best explain the evolution of the distribution of population at the local level. Then, among the physical factors, altitude was particularly relevant (Factor: "altitude"; Tables 2 and 3), whereas linear axes, coast (Factor: "distance from coast"; Tables 2 and 3) and railway (Factor: "distance from railway"; Tables 2 and 3 ) were less significant.

The factor relating to the country (Factor: "country"; Tables 2 and 3) in which each local unit is located offers an insight into its growth with respect to that of the state to which it belongs. It is important to add that this factor is difficult to interpret due to the heterogeneity of the local units in each country. We studied this with respect to four Boolean variables: one for each of the countries studied. We concluded that over an extended period (1920-1960), the average growth of the local units in Spain and Portugal exceeded that of those in France. However, this tendency 


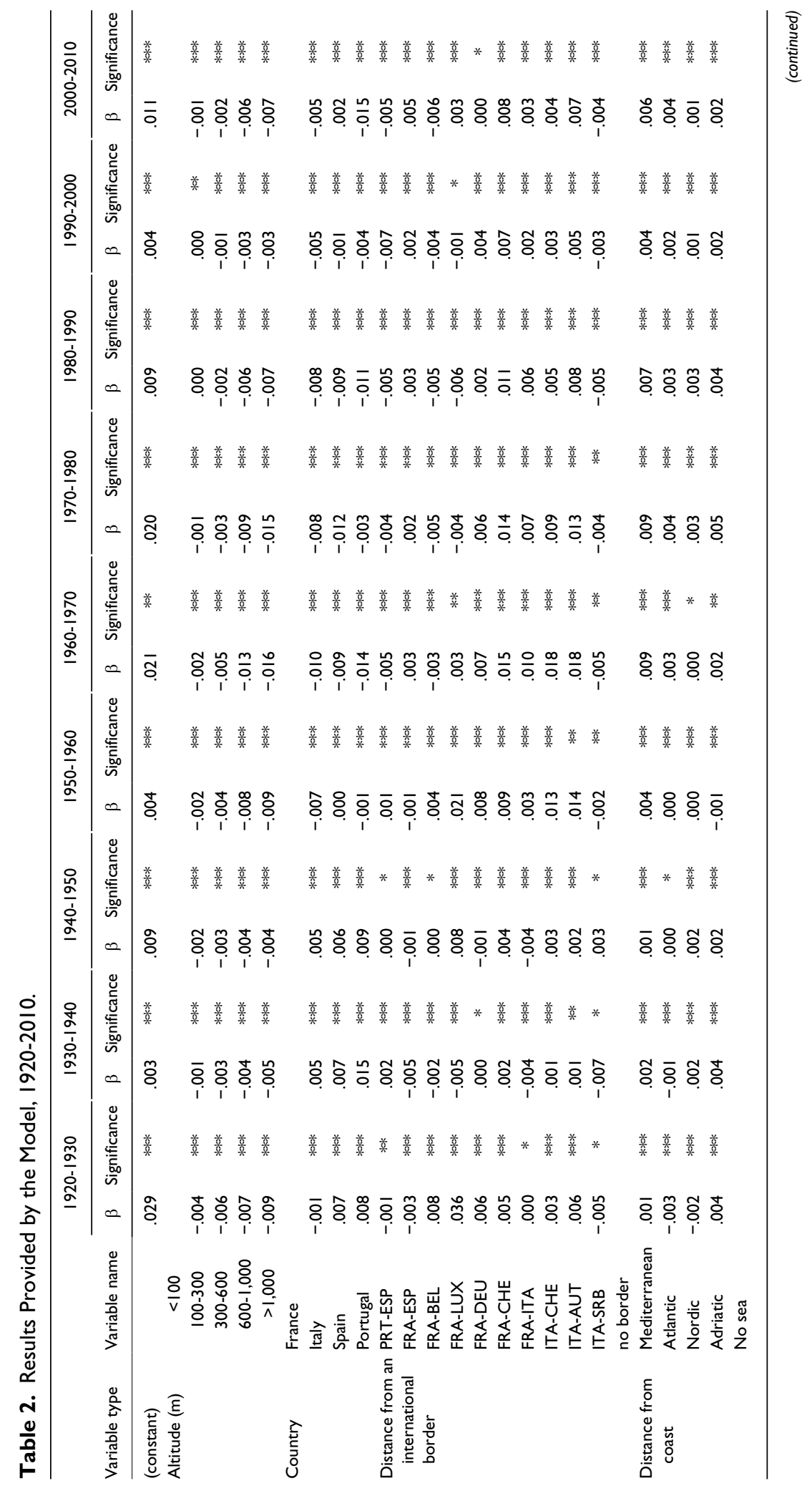




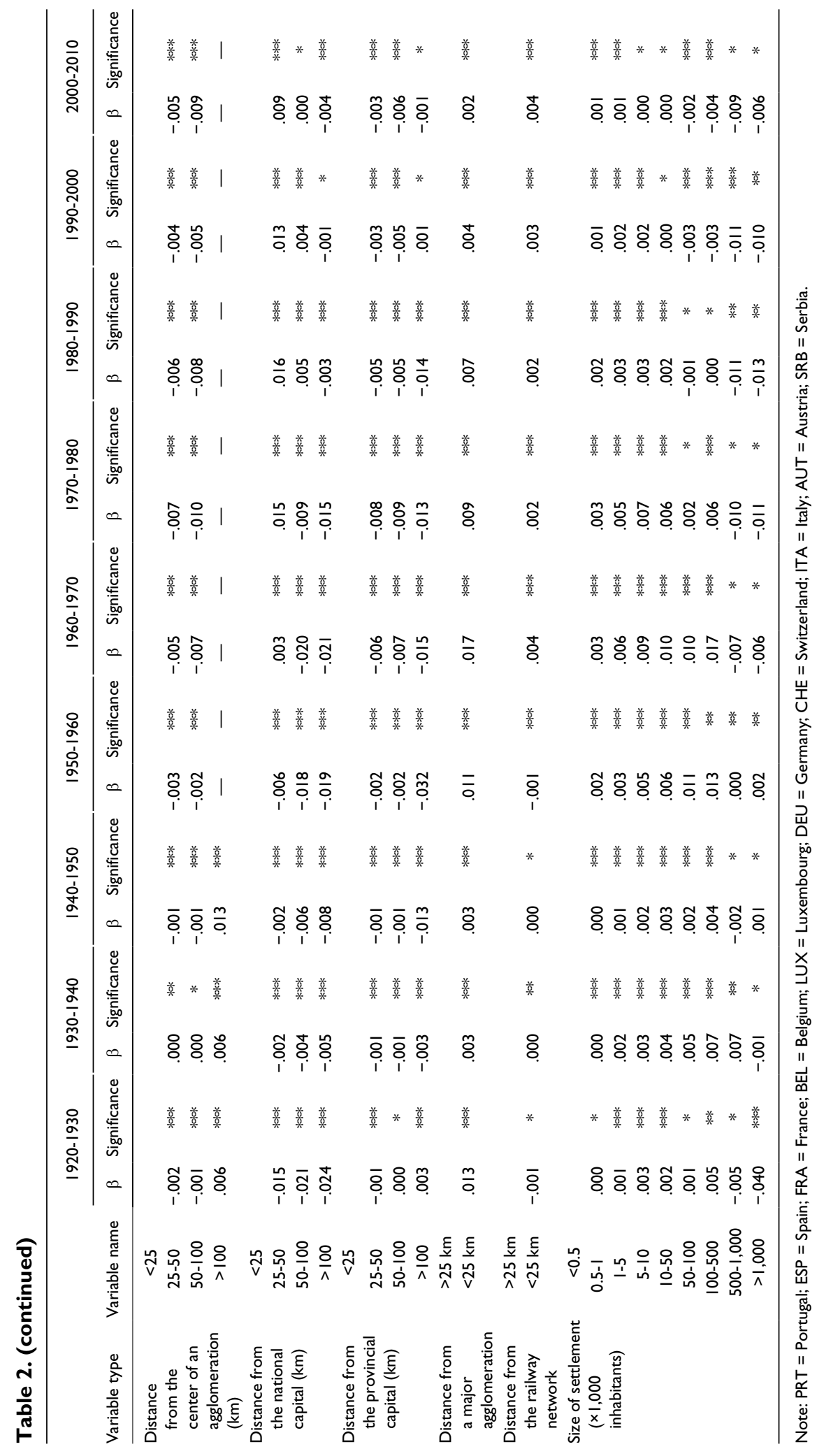


Table 3. Main Results Provided by the Model (1920-2010) Classified by Themes.

\begin{tabular}{llccc}
\hline $\begin{array}{l}\text { Themes of the } \\
\text { factors }\end{array}$ & \multicolumn{1}{c}{ Factors } & Minimum & Maximum & Amplitude \\
\hline State & Country & $-1.15 \%$ & $1.15 \%$ & $2.30 \%$ \\
& Distance from the national capital & $-2.40 \%$ & $1.60 \%$ & $4.00 \%$ \\
& Distance from the provincial capital & $-3.20 \%$ & $0.30 \%$ & $3.50 \%$ \\
Size and place of & Distance from an international border & $-0.70 \%$ & $\mathbf{2 . 1 0 \%}$ & $2.80 \%$ \\
concentration & Size of the municipality (population) & $-\mathbf{4} \%$ & $1.30 \%$ & $\mathbf{5 . 3 0 \%}$ \\
of population & Distance from a major urban agglomeration & $0.20 \%$ & $1.70 \%$ & $1.50 \%$ \\
Physical factors & Distance from the center of an agglomeration & $-1 \%$ & $1.30 \%$ & $2.30 \%$ \\
\multirow{2}{*}{ Networks } & Altitude & $-0.90 \%$ & $1.60 \%$ & $2.50 \%$ \\
& Distance from the coast & $-0.30 \%$ & $0.90 \%$ & $1.20 \%$ \\
\hline
\end{tabular}

Note: Boldfaced values correspond to the extreme value of each column: minimum, maximum, amplitude.

reversed from 1960 onward, when it was the French "communes" that globally grew most. In contrast, taken as a whole, the Italian local units grew least.

If we consider now the case of the population variable expressed in absolute numbers (Factor: "size of the settlement (population)"; Tables 2 and 3), we should refer to the number of inhabitants in the local unit at the beginning of each decade. We classified this indicator into the following groups, each of which was converted into a binary variable. ${ }^{37}$

According to the model, it was the group of local units between one hundred thousand and five hundred thousand inhabitants that experienced the greatest growth, in percentage terms, over the whole study period, followed by that with fifty thousand to one hundred thousand inhabitants. In contrast, the group of local units with more than one million inhabitants was the one that exhibited least growth in percentage terms. However, it is important to add that as these are local units that already have large populations, they would require a proportionally greater growth (in absolute numbers) to achieve high beta values.

The altitude factor (Factor: "altitude"; Tables 2 and 3) was divided into the following groups: local units located at below $100 \mathrm{~m}$; between 100 and $300 \mathrm{~m}$; between 300 and $600 \mathrm{~m}$; between 600 and 1,000 $\mathrm{m}$; and above $1,000 \mathrm{~m}$. The model showed that for the whole period, higher altitude was associated with lower population growth. It is important to underline the fact that these differences increased in the period 1950-1990, during which the local units located at altitudes above $600 \mathrm{~m}$ were particularly affected by the exodus. In 1980, the group of local units located above $1,000 \mathrm{~m}$ produced a beta coefficient of -0.013 , while for those below $100 \mathrm{~m}$, it was $0.009(0.9 \%)$.

For the factor relating to distance from an international border (Factor: "distance from an international border"; Tables 2 and 3), local units located less than $25 \mathrm{~km}$ from the nearest border were grouped together. However, changes in European borders during the twentieth century meant that it was necessary to recalculate these distances for each decade. These border changes have not been shown in the different figures presented in this article.

The conclusion is that, in practically every period, the local units that were most distant from international borders ("no border" class; Table 2) exhibited greater growth than those near to borders, with coefficients of between -0.007 and 0.021 . Even so, it is possible to particularly highlight the low values for local units near the Spanish-Portuguese ("PRT-ESP" class; Table 2) border, which is an economically underdeveloped region (from 1960 onward, the coefficients were below -0.004). This region contrasts with the French local units located near the border with Switzerland ("FRACHE"; Table 2), which had values above 0.007 for the same period. The effect of people who work in Switzerland but decide to live in France no doubt had an important influence on this finding.

A similar procedure was followed to calculate the influence of proximity to the coast (Factor: "distance from the coast"; Tables 2 and 3). The local units were grouped together according to the 
distance to the nearest coast whenever this was equal to or less than $25 \mathrm{~km}$. In this case, unlike that of the distance from national borders, the reference was constant throughout the study period ("no sea" class; Table 2).

The local units that exhibited the greatest growth were located along the Mediterranean coast; to be more specific, between 1960 and 1980, the value was $0.9 \%$ greater ("Mediterranean"; Table 2) than in local units located farthest from the coast ("no sea"). During the same period, the local units near the Atlantic coast grew by 0.3 percent to 0.4 percent ("Atlantic") more than those distant from the coast ("no sea"). In the case of local units located near the Adriatic Sea ("Adriatic"), these differences ranged from 0.2 percent to 0.5 percent for the same period. There was, therefore, a clear tendency for local units located at greater distances ("no sea") from the coast to experience lower rates of growth.

Then, to quantify the influence of proximity to a major urban agglomeration (Factor: "distance from a major urban agglomeration"; Tables 2 and 3), we classified the local units according to whether this distance was greater than or less than $25 \mathrm{~km}$. We started by using Geopolis to identify the urban agglomerations with populations of more than five hundred thousand. Given that new urban agglomerations have been formed over time, there have been changes in the group of local units over the period. To be more precise, the 965 local units located at short distances (less than 25 $\mathrm{km}$ ) from a major urban agglomeration in 1920 had become 2,757 by 2000 (3.18\% of the total number of local units). The result of the calculation was that the local units located at distances of less than $25 \mathrm{~km}$ from the center of a major agglomeration generally experienced greater growth than those farther away. This was particularly notable in the period 1960-1970, during which this type of local unit registered average levels of annual growth of 1.7 percent. These were greater than in the local units that were farther away from the major urban agglomerations. This implied the existence of currents of migration toward the larger agglomerations and their immediate surroundings. However, by the end of this period, this value had fallen to 0.2 percent.

Following this approximation, but with greater precision, we grouped the local units together according to whether the distance was less than $25 \mathrm{~km}$, from 25 to $50 \mathrm{~km}$, from 50 to $100 \mathrm{~km}$, or more than $100 \mathrm{~km}$ from the center of any urban agglomeration with more than 10,000 inhabitants (Factor: "distance from the center of an agglomeration"; Tables 2 and 3). It was also possible to show that the distance from the center of urban agglomerations was relevant and that from the 1950s onward, a distance of more than $25 \mathrm{~km}$ generally implied less growth. Based on these data, local units located between 25 and $100 \mathrm{~km}$ from urban agglomerations experienced growth of between -0.2 percent and -1 percent, which is less than those located less than $25 \mathrm{~km}$ from them. In contrast, the appearance of new urban agglomerations throughout the territory meant that from 1950 onward, no local unit was located more than $100 \mathrm{~km}$ from the center of an urban agglomeration.

The four ranges of distance from a local unit to its national and provincial capitals (less than 25 $\mathrm{km}$, between 25 and $50 \mathrm{~km}, 50$ and $100 \mathrm{~km}$, and more than $100 \mathrm{~km}$ ) have been defined based on the areas of the four countries studied and the average areas of their provinces. These are $5,665 \mathrm{~km}^{2}$ for the "departements" of France (where the area of the country is $543,700 \mathrm{~km}^{2}$ ), 2,925 $\mathrm{km}^{2}$ for the "province" in Italy (for a total area of 301,400 km²), 9,705 km² for the "provincias" of Spain (total country area 504,750 $\mathrm{km}^{2}$ ), and 4,581 for the "distritos" of Portugal (total country area 91,640 $\mathrm{km}^{2}$ ). National and provincial capitals (Factor: "distance from the national capital," "distance from the provincial capital"; Tables 2 and 3) also contributed to the attraction of population to the local units in their immediate surroundings thanks to the services that they offered and the economic dynamics that this implied. The result of the calculation indicated that this was particularly true in the case of the local units located nearest to the national capitals during the period 1970-1980. However, a great distance from a capital had a negative influence on growth and particularly so in the case of local units at distances of more than $100 \mathrm{~km}$ from a provincial capital. To be more precise, during the period 1940-1990, there was a negative difference in their growth of between -3.2 percent and -1.3 percent with respect to the local units located at distances of less than $25 \mathrm{~km}$.

Finally, we considered that local units enjoyed connections to the railway network when they were located at a distance of less than $25 \mathrm{~km}$ from the nearest line (Factor: "distance 
from railway"; Tables 2 and 3). Even if the distance to a station would be more pertinent than the distance to the railway, the latter supposes in some ways the proximity of a station. Even so, the coefficients for this variable were very close to zero for the whole period, but always higher for the local units that were nearest the railway network, and especially so during the decade 19601970, with growth of greater than 0.4 percent with respect to those that lacked such proximity.

\section{Conclusion}

Between 1920 and 2010, Europe experienced a constant but uneven growth in its population. During the ninety years of the study period, its population grew by 70 percent in spatial and temporal terms. The territorial disparities in population continued to increase and particularly so from the 1950s onward. It was in this period that the capitals, major urban agglomerations, and coastal local units gained more inhabitants at the expense of the others.

As our societies are predominantly urban, the distribution of population is mainly analyzed with respect to the city network. The originality of our approach lies in the fact that we have considered all locations - both urban and rural — when studying the territory. After all, each urban settlement first appeared in what was a rural area. Furthermore, to understand the concentration of population in large cities, it is also necessary to consider the spaces that surround them.

The originality of this article lies, on one hand, in the methodology used to exploit the data series on local population for the period 1920-2010 and, on the other, in a model of statistical analysis that is appropriate for these data. We have shown the value of having access to harmonized local population data for the four countries in SW Europe: France, Spain, Portugal, and Italy, during a period spanning almost a century. This has made it possible to open up new perspectives: on one hand, to explain the evolution of population in this part of Europe and, on the other, to develop a statistical model that is useful for undertaking a historical analysis of a large territory.

The descriptive analysis of these data shows very different trajectories from one country to another. All four of the countries that we studied went through the different phases that are characteristic of demographic and population change in the twentieth century: general population growth, urbanization, the emergence of urban agglomerations, urban concentration, rural depopulation, the formation of metropolitan areas, and finally metropolitanization. ${ }^{38}$ This has led to population dispersion, ${ }^{39}$ apparently limitless urban sprawl, ${ }^{40}$ and the emergence of new forms of settlement or metropolitan areas.$^{41}$ As we have seen, these phases occurred simultaneously in all of these countries.

This analysis was supported by the regression model that was presented. According to this model, the most relevant factors are capital status, altitude, and the population size of the local units. In contrast, the least relevant is proximity to the railway network.

The challenge for the model was the robustness of its character, given the heterogeneity of these data. It was, therefore, necessary to adapt them to a totally experimental focus. The variables are, by nature, very different and refer to various units of measurement. The work of harmonizing and normalizing these data is fundamental to the design of the model. As a result, this model could also be used to evaluate the factors that explain local dynamics in other areas.

It is, therefore, evident how, in the course of the twentieth century, not only did new urban agglomerations appear, but these then continued to grow. The other local units also experienced greater growth when located near an important nucleus of population. In the same way, and as shown by the maps and model, the local units nearest the coast were the ones that experienced the greatest growth, especially along the Mediterranean coast from the 1960s onward.

We have, therefore, seen how the linear regression model and cartography have provided us with a complementary vision of disparities in population growth in SW Europe. The cartography provides a more visual, geographical perspective. However, the model quantifies this reality and provides a more analytical vision. Both of these approaches are valid for discovering and better understanding the society in which we live. 


\section{Appendix}

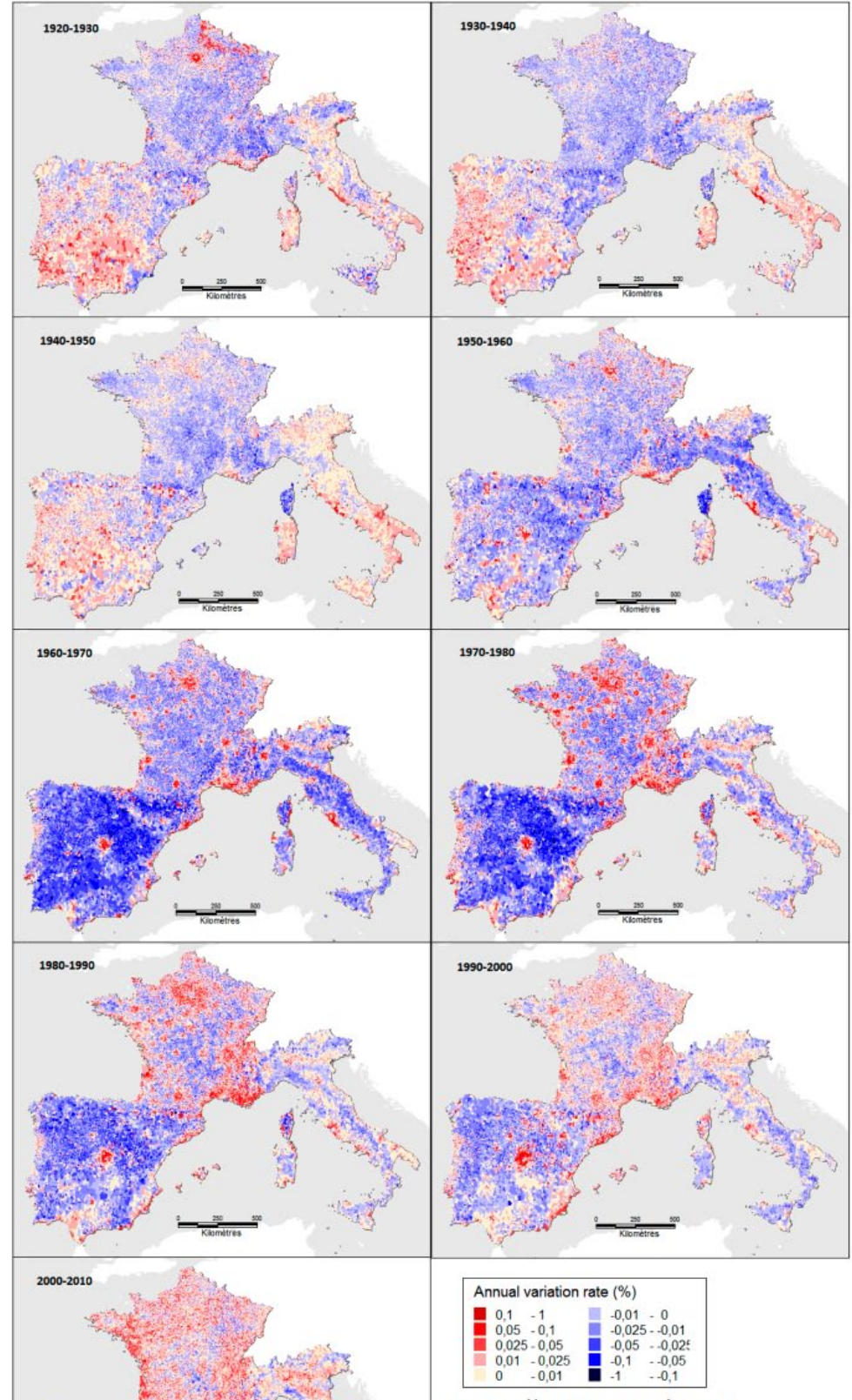

Source : Geokhoris 2012. e-Geopolis project Map : C. Chatel, 2014.

Population density by local administrative units, by decade, 1920-20 I0. 


\section{Acknowledgments}

Special thanks to Dr. François Moriconi-Ebrard for Geokhoris and Geopolis data availability.

\section{Declaration of Conflicting Interests}

The authors declared no potential conflicts of interest with respect to the research, authorship, and/or publication of this article.

\section{Funding}

The authors disclosed receipt of the following financial support for the research, authorship, and/or publication of this article: This research has been funded by (1) European Union (EU; Jean Monnet 586912-EPP1-2017-1-ES-EPPJMO); (2) Institució Catalana de Recerca i Estudis Avançats (ICREA), Generalitat de Catalunya; (3) ANR Corpus et outils de la recherche en sciences humaines et sociales (CORP) 2007 ANR07-CORP-0019; (4) Ministerio de Economia y Competitividad: CSO2015-65733-P; and (5) RecerCaixa.

\section{Notes}

1. Doreen Massey, "In What Sense a Regional Problem?," in Space, Place and Gender, ed. Doreen Massey (Minneapolis: University of Minnesota Press, 1994), 50-66.

2. Doreen Massey, "Politics and Space/Time," New Left Review 196 (1992): 65-84.

3. Neil Smith, "New Globalism, New Urbanism: Gentrification as Global Urban Strategy," Antipode 34, no. 3 (2002): 427-50.

4. Neil Brenner, "The Limits to Scale? Methodological Reflections on Scalar Structuration," Progress in Human Geography 25, no. 4 (2001): 591-614.

5. Paul Bairoch and Gary Goertz, "Factors of Urbanisation in the Nineteenth Century Developed Countries: A Descriptive and Econometric Analysis," Urban Studies 23, no. 4 (1986): 285-305.

6. James Lutz, "Determinants of Population Growth in Urban Centres in the Republic of Ireland," Urban Studies 38, no. 8 (2001): 1329-40.

7. François Moriconi-Ebrard, L'urbanisation du Monde depuis 1950 (Paris: Anthropos, 1993). (EN: The world urbanization since 1950)

8. Paul Bairoch and Gary Goertz, "Factors of Urbanisation in the Nineteenth Century Developed Countries," 285-305.

9. James Lutz, "Determinants of Population Growth in Urban Centres in the Republic of Ireland," $1329-40$.

10. Robert Schwartz, Ian Gregory, and Thomas Thévenin, "Spatial History: Railways, Uneven Development, and Population Change in France and Great Britain, 1850-1914," Journal of Interdisciplinary History 42, no. 1 (2011): 53-88.

11. Xavier Franch, Jordi Marti-Henneberg and Josep Puig-Farré "Un análisis espacial de las pautas de crecimiento y concentración de la población a partir de series homogéneas: España (1877-2001), Investigaciones Regionales 25 (2013): 43. (EN: A spatial analysis of population growth and concentration patterns from homogeneous series: Spain (1877-2001)"

12. Jean-Pierre Bardet and Jacques Dupâquier, Histoire des Populations de l'Europe, (EN: History of populations in Europe) vol. 3 (Paris: Fayard, 1997-1999).

13. Paul Bairoch and Gary Goertz, "Factors of Urbanisation in the Nineteenth Century Developed Countries," 285-305.

14. James Lutz, "Determinants of Population Growth in Urban Centres in the Republic of Ireland," $1329-40$.

15. Schwartz and al., "Spatial History," 53-88.

16. Xavier Franch, Jordi Marti-Henneberg and Josep Puig-Farré., "Un análisis espacial de las pautas de crecimiento y concentración de la población a partir de series homogéneas," 43. (EN: A spatial analysis of population growth and concentration patterns from homogeneous series: Spain (1877-2001)

17. Ivan Turok and Vlad Mykhnenko, "The Trajectories of European Cities, 1960-2005," Cities 24, no. 3 (2007): 165-82.

18. Jordi Martí-Henneberg, "Empirical Evidence of Regional Population Concentration in Europe, 18702000," Population, Space and Place 11 (2005): 269-81. 
19. Richard Morrill, "Fifty Years of Population Change in the US 1960-2010," Cities 29 (2012): 29-40.

20. Ian N. Gregory and Alistair Geddes, Toward Spatial Humanities: Historical GIS and Spatial History (Bloomington: Indiana University Press, 2014).

21. For example: Vision of Britain project (http://www.visionofbritain.org.uk/); Historical GIS Research Network (http://www.hgis.org.uk/index.htm); Humanities GIS Projects (http://geohumanities.org/ about).

22. Donald A. DeBats and Ian N. Gregory, ed. Special Edition on "Historical GIS and the Study of Urban History," Social Science History 35, no. 4 (2011): 455-463; Jordi Marti-Henneberg, ed. Special Edition on "Railways, Population and Geographical Information Systems," Journal of Interdisciplinary History 42, no. 1 (2011): 1-13.

23. Francisco J. Goerlich Gisbert and Matilde Mas Ivars, ed. La localización de la población española sobre el territorio: Un siglo de cambios. Un estudio basado en series homogéneas (1900-2001) (Bilbao: Fundación BBVA, 2006) (EN: The location of the Spanish population on the territory: A century of changes. A study based on homogeneous series (1900-2001)); Juan Pons Izquierdo, Dolores López, and Carolina Montoro Gurich, "Del interior a la costa: dinámica espacial de la población espanola a lo largo del siglo XX," in VII Congresso de la Asociación de Demografía Histórica, 1-3 april 2014 (Granada, 2004): 1-3 (EN: From the interior to the coast: spatial dynamics of the Spanish population throughout the 20th century); Luís Espinha da Silveira, Daniel Alves, Marco Painho, Ana Cristina Costa, and Ana Alcântara, "The Evolution of Population Distribution on the Iberian Peninsula: A Transnational Approach (1877-2001)," Historical Methods: A Journal of Quantitative and Interdisciplinary History 46, no. 3 (2013): 157-74; see also: http://atlas.fcsh.unl.pt/cartoweb35/ atlas.php?lang=pt; Jean-Pierre Bardet Jacques Dupâquier, and Laboratoire de démographie de l'École des hautes études en sciences sociales ed. Paroisses et communes de France : dictionnaire d'histoire administrative et démographique (Paris: CNRS editions): one volume for one or various french departements, Publication in progress since 1974 (EN: Parishes and communes of France : dictionary of administrative and demographic history); Claude Motte, Isabelle Séguy, and Christine Théré, Communes d'hier, communes d'aujourd'hui: les communes de la France métropolitaine, 1801-2001, dictionnaire d'histoire administrative (Paris: Ined, 2003) (EN: Communes of yesterday, communes of today: the communes of metropolitan France, 1801-2001, dictionary of administrative history); see also: http://cassini.ehess.fr/cassini/fr/html/1_navigation.php.

24. Ian N. Gregory, "The Accuracy of Areal Interpolation Techniques: Standardising 19th and 20th Century Census Data to Allow Long-Term Comparisons," Computers, Environment and Urban Systems 26, no. 4 (2002): 293-314.

25. Cathy Chatel, "Dynamiques de peuplement et transformations institutionnelles. Une mesure de l'urbanisation en Europe de 1800 à 2010" (Thesis, Université Paris, 2012). (EN: Population dynamics and institutional transformations. A measure of urbanization in Europe from 1800 to 2010).

26. For example, 4,873 communes in France have been abolished or merged between the first and the last census (1793 to 2011).

27. Website of the project "HGISe: Railways, Road and Waterways" .

28. Mateu Morillas-Torné, , "Creation of a Geo-Spatial Database to Analyse Railways in Europe: A Historical GIS Approach," Journal of Geographic Information System 4, no. 2 (2012): 176-87.

29. Due 2016.

30. François Moriconi-Ebrard, Geopolis, Pour comparer les villes du monde (Paris: Anthropos, 1994). (EN: Geopolis, To compare the cities of the world).

31. Ian N. Gregory, Jordi Marti-Henneberg and Francisco J. Tapiador., "Modelling Long-Term PanEuropean Population Change from 1870 to 2000 by Using Geographical Information Systems," Journal of the Royal Statistical Society: Series A (Statistics in Society) 173, no. 1 (2010): 31-50.

32. This calculation was performed with the GeoDa spatial analysis software, developed by researchers at the Center for Geospatial GeoDa Analysis and Computation: http://geodacenter.asu.edu/. Luc Anselin, Ibnu Syabri, and Youngihn Kho, "GeoDa: An Introduction to Spatial Data Analysis," Geographical Analysis 38, no. 1 (2006): 5-22.

33. A. Stewart Fotheringham, Chris Brunsdon, and Martin Charlton, Geographically Weighted Regression: The Analysis of Spatially Varying Relationships (Chichester: John Wiley, 2003).

34. For example, the distance of each locality from the nearest national border is in series because boundaries have changed. However, the altitude of each locality is constant for the whole period. 
35. The number of local administrative units varies greatly, and this conditions its population density. For instance, the average surface area of the local units in Spain is $62 \mathrm{~km}^{2}$, while it is 37 in Italy, 23 in Portugal, and 15 in France.

36. In Spain, Madrid, and Barcelona; in Italy, Rome, Milan, and Naples; in Portugal, Lisbon, and Porto.

37. Fewer than 500 inhabitants; from 500 to 1,000 ; from 1,000 to 5,000 ; from 5,000 to 10,000 ; from 10,000 to 50,000 ; from 50,000 to 100,000 ; from 100,000 to 500,000 ; from 500,000 to $1,000,000$; and more than $1,000,000$. Each local unit was assigned to only one group, with the possibility of it changing to another in other decades, according to its growth.

38. François Ascher, Metápolis (Paris: Odile Jacob, 1995).

39. Francisco J. Monclús, Ciudad dispersa y ciudad compacta. Perspectivas urbanísticas sobre las ciudades mediterráneas, no. 7 (Girona: D’Humanitats, 1999), 95-110. (EN: Scattered city and compact city. Urbanistic perspectives on Mediterranean cities)

40. Robert Bruegmann, Sprawl: A Compact History (Chicago, IL: The University of Chicago Press, 2005).

41. Francesco Indovina, La città diffusa (Venezia: Dipartamento di Analisi Economica e Sociale del Territorio, Istituto Universitario di Architettura di Venezia, 1990). (EN: The widespread city)

\section{Author Biographies}

Cathy Chatel has received a $\mathrm{PhD}$ for "Population Dynamics and Institutional Changes: A Measure of Urbanization in Europe from 1800 to 2010," from Paris VII (June 2012). She has demonstrated that detailed population data for Europe can help to explain various features of Europe's urban population such as the large number of small urban population agglomerations, the relative absence of very large urban population agglomerations, and Europe's relatively recent urbanization process. She is in charge of population data. She also completed a postdoctoral research about urbanization of Brazil at the State University of São Paulo (UNESP), funded by the São Paulo Research Foundation (FAPESP).

Mateu Morillas-Torné focused his research on the effect of the railways in the distribution of population in Europe. He is also interested in the evolution of the population in Spain at the municipal level.

Albert Esteve is the director of the Centre d'Estudis Demogràfics (CED) at the Universitat Autonoma de Barcelona, Spain. He is in close contact and collaboration with the Office of Population Research and Center for Migration and Development at Princeton University, New Jersey.

Jordi Martí-Henneberg, over the last twelve years, has mainly focused his research work on European Integration (EI). He thinks that to understand the process of institutional integration since 1958, it is necessary to adopt a broader historical perspective. This view has inspired his teaching on European Integration for the last fifteen years, which has been partly supported by Jean Monnet grants. The use of dedicated portals for a better knowledge of EI has been one of his main recent interests. 